\title{
Forschung $\mathrm{OStudium}$ \\ QAnglistik 4
}

Herausgegeben von

Wolf-Dietrich Bald, Rudolf Emons und Leonhard Lipka 

Peter Erdmann

\section{Discourse and Grammar}

Focussing and defocussing in English

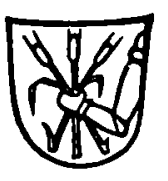

Max Niemeyer Verlag Tübingen 1990 
CIP-Titelaufnahme der Deutschen Bibliothek

Erdmann, Peter : Discourse and grammar : focussing and defocussing in English / Peter Erdmann. - Tübingen : Niemeyer, 1990

(Forschung \& [und] Studium Anglistik ; 4)

NE: GT

ISBN 3-484-41004-3 ISSN 0178-7861

(c) Max Niemeyer Verlag GmbH \& Co. KG, Tübingen 1990

Das Werk einschlieBlich aller seiner Teile ist urheberrechtlich geschützt. Jede Verwertung außerhalb der engen Grenzen des Urheberrechtsgesetzes ist ohne Zustimmung des Verlages unzulässig und strafbar. Das gilt insbesondere für Vervielfältigungen, Übersetzungen, Mikroverfilmungen und die Einspeicherung und Verarbeitung in elektronischen Systemen. Printed in Germany.

Druck: Weihert-Druck GmbH, Darmstadt 